Article

\title{
Fabrication and Tribological Properties of Mesocarbon Microbead-Cu Friction Composites
}

\author{
Hai-Xia Guo and Jian-Feng Yang * \\ State Key Laboratory for Mechanical Behavior of Materials, Xi'an Jiaotong University, Xi'an 710049, China; \\ guohx2011@163.com \\ * Correspondence: yang155@mail.xjtu.edu.cn
}

Received: 25 October 2019; Accepted: 15 January 2020; Published: 18 January 2020

\begin{abstract}
Graphite-metal composites have been used as friction materials owing to their self-lubricity, which is ascribed to the weak interlayer bonding of graphite. To overcome the shortage of graphite flake (GrF)-filled composites of having low tribological properties, graphite-Cu composites with mesocarbon microbead (MCMB) as the solid lubricant are developed in this paper. The MCMB-Cu composites have a lower friction coefficient and wear rate than do the $\mathrm{GrF}-\mathrm{Cu}$ composites taken as reference materials, exhibiting a better self-lubricating performance. Microstructural analysis indicates that the relatively weaker interlayer bonding of the $\mathrm{MCMB}$, smooth interface between the $\mathrm{MCMB}$ and matrix, and more cementite formation thorough reaction of $\mathrm{MCMB}$ and iron are the key factors behind the enhanced tribological properties. In addition, both the friction coefficients and wear rates of the two groups of composites gradually decrease with the graphite content. This work opens an avenue for designing desirable graphite-based metal friction materials.
\end{abstract}

Keywords: $\mathrm{Cu}$-matrix composites; mesocarbon microbead; mechanical property; tribological behavior

\section{Introduction}

Copper and its alloys have high potentials for use in tribological applications, such as electrical contacts, bearings, and bushings, owing to their superior corrosion resistance and electrical and thermal conductivity [1-3]. However, their poor wear resistance and the failure of liquid lubricants under extreme conditions restrict their potential to some extent. Incorporating solid lubricants (such as graphite, $\mathrm{MoS}_{2}$, and h-BN) and ceramic particles (i.e., $\mathrm{Al}_{2} \mathrm{O}_{3}, \mathrm{FeCr}$, and $\mathrm{SiC}$ ) into the copper matrix is an effective approach for achieving high wear resistance and self-lubricity [4-9]. Graphite has been widely used as a solid lubricant within copper matrices owing to its good lubricity and easy availability. It exhibits differences in the aspects of type, size, and shape, which govern the lubricating properties of the composites. Accordingly, understanding the influences of these factors and the lubrication mechanisms can help in the design of advanced metal matrix composites with desirable self-lubricating performances.

A great deal of effort has been devoted to exploring the effects of graphite on the wear resistance and self-lubricity of $\mathrm{Cu}$-matrix composites. For example, Rajkumar and coworkers [10] investigated the effects of the amount of graphite on the self-lubricity of copper-TiC-graphite composites. They found that $\mathrm{Cu}$-matrix composites with high graphite contents showed good wear resistance. Zhan et al. [11] demonstrated that the wear resistance of copper-SiC-graphite composites increased as the amount of graphite increased under low loads, while the situation reversed with high graphite contents under high loads. Similar results have also been observed by Wang et al. [12] and Chen et al. [13]. In addition to graphite flakes, other kinds of graphite including expanded graphite and graphene nano-platelets have also been used to improve the wear resistance of $\mathrm{Cu}$-based composites $[12,14]$. 
In these studies, the types of graphite used were irregular flakes. Their sharp shapes caused obvious stress concentrations at the contact surfaces between the graphite and matrix and interfacial failure under loading, hindering the enhancement of the wear resistance of the composites to a certain extent. On the other hand, a larger interlayer spacing results in weaker interlayer bonding [13] in the crystalline structure of graphite, which leads to easier delamination between adjacent interlayers under loading. In this situation, thinner graphite sheets are sheared off during shear-friction processes, which results in easy formation of a solid lubricant film at the friction surface, thus reducing the wear rates of composites [12]. As a promising type of artificial graphite, mesocarbon microbead (MCMB) has a regular spheroidal shape with a layered structure after being graphitized, and exhibits high hardness and cycle stability $[15,16]$. Compared with graphite flakes, MCMBs have a smoother shape and a larger interlayer spacing (from $0.3405 \mathrm{~nm}$ to $0.3350 \mathrm{~nm}$ ) [17]. These features provide the possibility of achieving excellent wear resistance by introducing MCMB as a solid lubricant into metal matrices. However, to the best of our knowledge, there has been no reporting on MCMB-metal friction materials.

In this paper, therefore, $\mathrm{MCMB}-\mathrm{Cu}$ matrix composites are developed by vacuum hot-pressing technology, and their tribological properties are investigated for the first time, with graphite flake (GrF)-Cu composites used as the reference material. MCMB-metal matrix composites exhibit superior self-lubricating performance in comparison with $\mathrm{GrF}-\mathrm{Cu}$ composites. This work opens an avenue for the design of graphite-based metal friction materials.

\section{Experimental}

\subsection{Materials}

The spherical atomized copper (mean particle size: $2 \mu \mathrm{m}$, Shanghai Chaowei Nanotechnology Co., Ltd., Shanghai, China), elliptical reduced iron (mean particle size: $3 \mu \mathrm{m}$, Shanghai Chaowei Nanotechnology Co., Ltd., Shanghai, China), and rod-like aluminum (mean particle size: $57 \mu \mathrm{m}$, Shanghai Chaowei Nanotechnology Co., Ltd., Shanghai, China) of 99.9\% purity were mixed, and the mixture was used as the matrix of the MCMB-Cu composites. The particle size of alumina $(\sim 100 \mu \mathrm{m}$ magnitude) is frequently used as a reinforcement in metal matrix composites [18]. Therefore, clumpy alumina (mean particle size: $150 \mu \mathrm{m}$, Sinopharm Chemical Reagent Co., Ltd., Shanghai, China) of 99.0\% purity was employed as a reinforcement to improve the mechanical properties of the composites. Graphite flakes are the most common lubricant used in $\mathrm{Cu}$-matrix composites, and particle sizes of 30-50 $\mu \mathrm{m}$ are widely studied in metal matrix composites $[4,6,10]$. To reflect the improvement of the tribological properties of the MCMB-Cu composites developed in the present work, graphite flakes (mean particle size: $40 \mu \mathrm{m}$, Qingdao Jin Ri Lai Graphite Co., Ltd., Qingdao, China) of 99.0\% purity were selected to prepare $\mathrm{GrF}-\mathrm{Cu}$ composites as reference materials. MCMB (mean particle size: $40 \mu \mathrm{m}$, Tianjin Eminent Battery Material Co., Ltd., Tianjin, China) of $99.0 \%$ purity was used as the solid lubricant. In this case, the MCMB had a nearly spherical shape, while GrF had a cuboids shapes with approximate dimensions of $40 \mu \mathrm{m} \times 10 \mu \mathrm{m} \times 1 \mu \mathrm{m}$. The micromorphologies of the two types of graphite particles are shown in Figure 1.
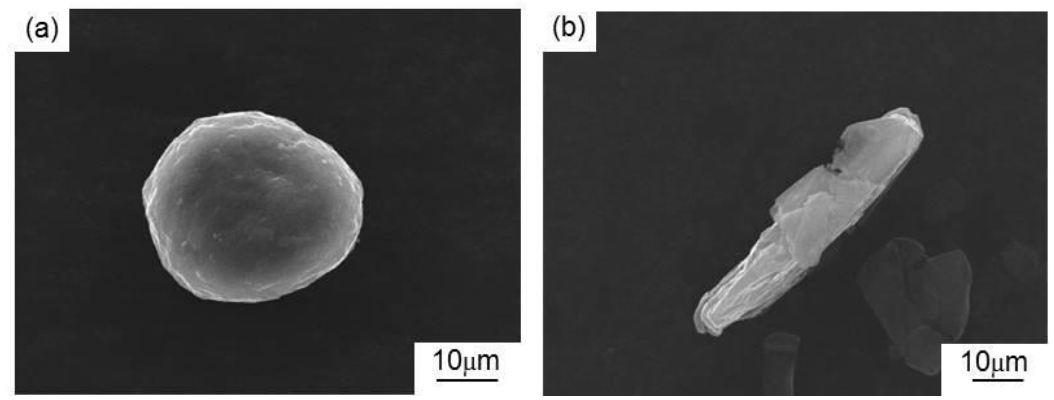

Figure 1. Micromorphologies of the as-received graphite: (a) mesocarbon microbead (MCMB) and (b) graphite flake $(\mathrm{GrF})$. 


\subsection{Preparation Method}

Vacuum hot-pressing technology was applied to prepare the MCMB-Cu composites. This is a method often used in the preparation of metal matrix composites $[13,19]$. The preparation process was as follows. First, the copper, iron, and aluminum particles were wet-milled for $6 \mathrm{~h}$ in a plastic bottle using high-purity alumina balls as the grinding medium and anhydrous alcohol as the dispersing agent. The resulting slurry was vacuum-dried in a rotary evaporator. Then, the dried mixture, MCMB, and alumina were dumped into in a V-type mixer and mixed for $30 \mathrm{~min}$. The powder mixture was poured into a graphite mold with a cylindrical groove, whose diameter and height were $30 \mathrm{~mm}$ and $8 \mathrm{~mm}$, respectively. The mold was deposited in a vacuum furnace (Highmulti-5000, Fujidempa Co. Ltd., Osaka, Japan) and sintered at $980^{\circ} \mathrm{C}$ for $1 \mathrm{~h}$ under a uniaxial pressure of $20 \mathrm{MPa}$. Then, the power was turned off, and the sample temperature was decreased from $980{ }^{\circ} \mathrm{C}$ to $250{ }^{\circ} \mathrm{C}$ at a cooling rate of $4{ }^{\circ} \mathrm{C} / \mathrm{min}$ in the furnace. Finally, the sample was removed from the furnace at room temperature after furnace cooling. The $\mathrm{GrF}-\mathrm{Cu}$ composites were fabricated by the preparation process used for the MCMB-Cu composites. The chemical compositions of these two composites are listed in Table 1. Depending on the different solid lubricants and their contents, the samples of these composites were named solid lubricant-n, in which solid lubricant includes MCMB and GrF and $\mathrm{n}$ denotes the solid lubricant volume content. For example, MCMB-5 represents the MCMB-Cu composite with 5 vol. $\%$ MCMBs.

Table 1. Chemical compositions (vol.\%) of the mesocarbon microbead (MCMB)-Cu composites and graphite flake (GrF)-Cu composites.

\begin{tabular}{ccccccc}
\hline Samples & $\mathbf{M C M B}$ & $\mathbf{G r F}$ & $\mathbf{A l}_{\mathbf{2}} \mathbf{O}_{\mathbf{3}}$ & $\mathbf{C u}$ & $\mathbf{F e}$ & $\mathbf{A l}$ \\
\hline MCMB-5 & 5.0 & 0 & 5.0 & 50.4 & 34.2 & 5.4 \\
MCMB-15 & 15.0 & 0 & 5.0 & 44.8 & 30.4 & 4.8 \\
MCMB-25 & 25.0 & 0 & 5.0 & 39.2 & 26.6 & 4.2 \\
GrF-5 & 0 & 5.0 & 5.0 & 50.4 & 34.2 & 5.4 \\
GrF-15 & 0 & 15.0 & 5.0 & 44.8 & 30.4 & 4.8 \\
GrF-25 & 0 & 25.0 & 5.0 & 39.2 & 26.6 & 4.2 \\
\hline
\end{tabular}

\subsection{Characterizations}

To characterize the crystalline structures of MCMB and GrF, their diffraction patterns were measured using X-ray diffraction (XRD) by means of an X-ray diffractometer (PW 1730, Philips, Eindhoven, The Netherlands) with monochromatic $\mathrm{CuK} \alpha$ radiation at $40 \mathrm{kV}$ and $40 \mathrm{~mA}$. The samples were scanned in the $2 \theta$ interval of $10^{\circ}-90^{\circ}$ at a scanning speed of $0.3^{\circ} / \mathrm{s}$ with $\mathrm{Si}$ as an internal standard. The Bragg equation is as follows:

$$
d=n \lambda / 2 \sin \theta
$$

in which $d$ is the interplanar spacing; $\theta$ is the Bragg angle; the diffraction series $n=1,2,3 \ldots$; and the

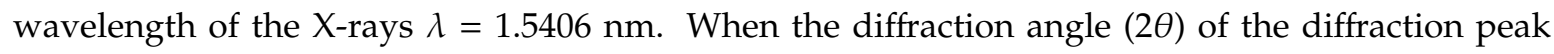
corresponding to the MCMB and GrF crystal plane was obtained, the interlayer distance $d$ of the MCMB and GrF could be obtained by Equation (1), in which the diffraction series (n) took the value of one.

The porosity and bulk density of the sintered products were measured by the Archimedes displacement method with distilled water as the immersion liquid.

The hardness values of the bulk prepared materials were measured using a Brinell testing machine (HBW-3000A, Shanghai Lianer Testing Equipment Co. Ltd., Shanghai China) with an indenter diameter of $5 \mathrm{~mm}$. The applied load and holding time were $250 \mathrm{~kg}$ and $30 \mathrm{~s}$, respectively. At least five replicates were performed for the hardness test for each specimen, and average values were obtained.

The flexural strengths of the samples were obtained by cutting, grinding, and polishing to dimensions of $2 \mathrm{~mm} \times 2 \mathrm{~mm} \times 25 \mathrm{~mm}$. The flexural strength was measured on an Instron 1196 machine (Instron Corporation, Boston, MA, USA) by the three-point bending method, with a $20.0 \mathrm{~mm}$ span and 
a cross-head speed of $0.5 \mathrm{~mm} / \mathrm{min}$. The specimen tensile side for the strength test was normal to the hot-pressing direction. At least five specimens were tested for each condition, and the standard error was calculated.

Scanning electron microscopy (SEM) (Phenom proX, Phenom-World BV, Eindhoven, The Netherlands) was used to examine the microstructures of the composites after etching in $4 \%$ nitric acid-alcohol solution.

The coefficients of friction and the wear characteristics of the $\mathrm{Cu}$ matrix composites were evaluated using a ball-on-disk tribometer (LFT-1, Lanzhou Zhongke Kaihua Technology Development Co., Ltd., Lanzhou, China). A commercially available GCr15 bearing ball with a measured average hardness of HRC61 and a diameter of $5 \mathrm{~mm}$ was used as the counterpart ball, and the prepared sample was used as the disc. Before testing, the composite disk samples and balls were cleaned using acetone in an ultrasonic bath for $15 \mathrm{~min}$, followed by drying in a vacuum oven at $70{ }^{\circ} \mathrm{C}$ for $0.5 \mathrm{~h}$. The bearing ball was kept stationary under an applied load of $50 \mathrm{~N}$, while the composite specimens were fixed on a disk in the tribometer. The disk could be actuated to repeatedly move along the surface with a constant stroke of $5 \mathrm{~mm}$ and a frequency of 500/min, which was the equivalent of a linear speed of $80 \mathrm{~mm} / \mathrm{s}$. All tests were carried out in air at room temperature (RT) with a humidity of $60 \%$. A sliding time of $30 \mathrm{~min}$ was used for each test. The wear tests were carried out in triplicate. The coefficient of friction was determined by an analog-to-digital converter, and simultaneously recorded by a computer during the wear test. The wear rate was calculated by the following equation:

$$
W=m / \rho L N
$$

where $m$ is the mass loss of the sample; $\rho$ is the density of the sample; $L$ is the total movement distance of the disk during the test; and $N$ is the pressure load applied on the bearing ball, with $N=50 \mathrm{~N}$.

The wear debris was collected after the friction test was completed. The morphologies of the frictional surfaces (worn surfaces) and wear debris were determined by SEM analysis to study the wear mechanisms.

\section{Results and Discussion}

\subsection{Microstructure Characterization}

Figure 2 reveals the microstructures of the MCMB-Cu composites. Figure 2a shows the SEM image of a typical MCMB-25 sample surface. The $\mathrm{MCMB}$ and $\mathrm{Al}_{2} \mathrm{O}_{3}$ particles are uniformly distributed throughout the $\mathrm{Cu}$ matrix without aggregation. $\mathrm{MCMB}$ or $\mathrm{Al}_{2} \mathrm{O}_{3}$ particles are in tight contact with the matrix, as shown in Figure 2e. There are no obvious defects, such as pores and cracks, at the interfaces between the $\mathrm{MCMB}$ or $\mathrm{Al}_{2} \mathrm{O}_{3}$ particle and matrix, indicating sintering compaction of the sample. In addition, Figure $2 b$ shows the SEM image of a typical GrF-25 sample surface. $\mathrm{GrF}$ and $\mathrm{Al}_{2} \mathrm{O}_{3}$ particles are also distributed within the $\mathrm{Cu}$ matrix. The two kinds of composites exhibit similar structures.

To further prove the compactness of the sample, the densities and porosities of the two groups of composites are shown in Table 2. When the relative density of a composite is as high as $95 \%$, it is a compact material [19]. It can be seen that, when the MCMB or GrF content reached 25\%, the relative density of the composite was still as high as $96 \%$. This results showed that the sample was compact. This result also indicated the successful preparation of these composites using the vacuum hot-press method. 

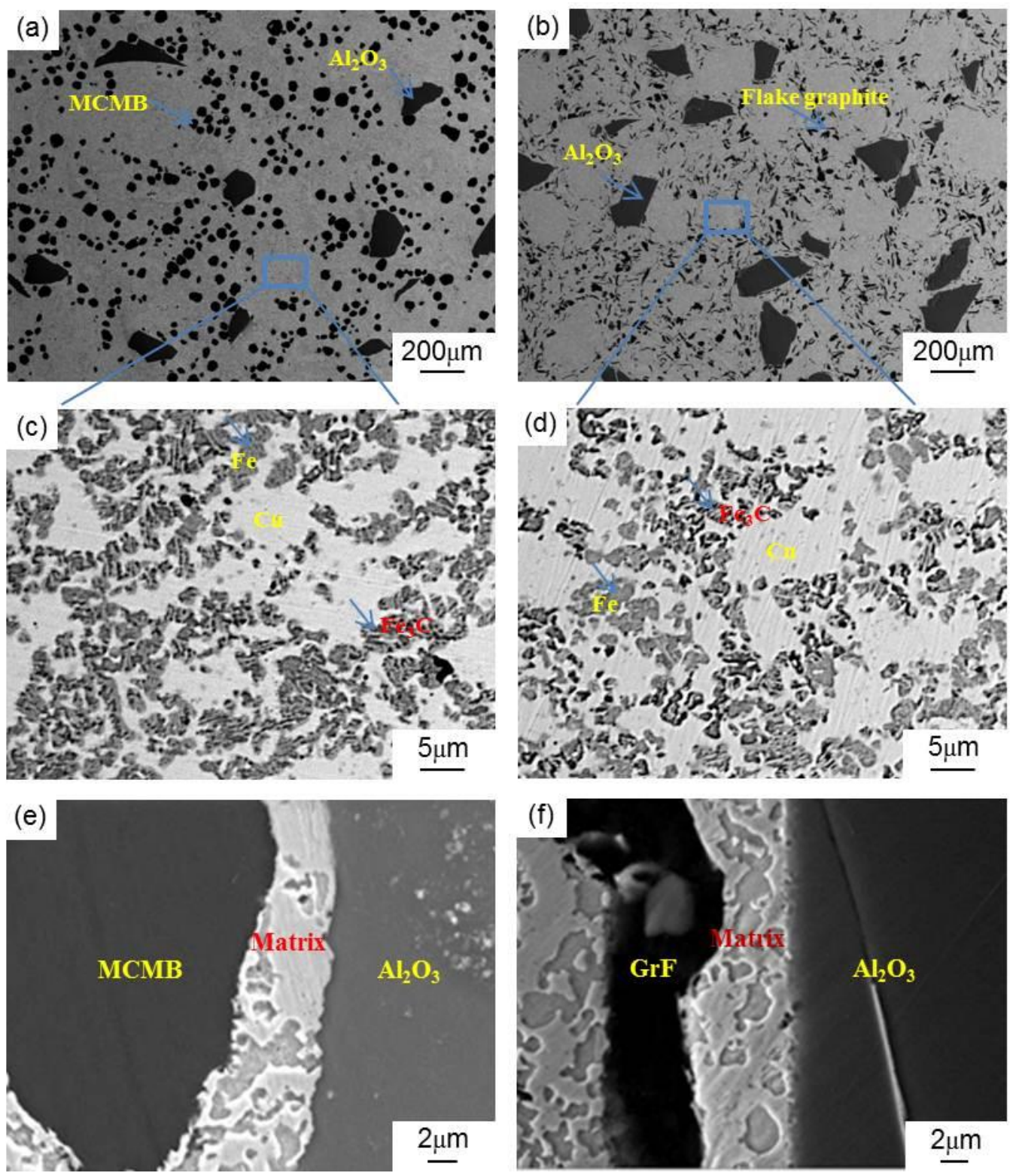

Figure 2. Scanning electron microscopy images (SEM) of the (a,e) MCMB-25 and (b,f) GrF-25 composites, and the backscatter electron image (BSEM) of the matrices of the (c) MCMB-25 and (d) GrF-25 composites.

Table 2. Densities and porosities of MCMB-Cu composites and GrF-Cu composites.

\begin{tabular}{|c|c|c|c|c|}
\hline Samples & $\begin{array}{c}\text { Theoretical } \\
\text { Density }\left(\mathrm{g} / \mathrm{cm}^{3}\right)\end{array}$ & $\begin{array}{l}\text { Bulk Density } \\
\qquad\left(\mathrm{g} / \mathrm{cm}^{3}\right)\end{array}$ & $\begin{array}{l}\text { Relative Density } \\
(\%)\end{array}$ & Porosity (\%) \\
\hline MCMB-5 & 7.62 & 7.43 & 97.51 & 2.49 \\
\hline MCMB-15 & 7.03 & 6.95 & 98.72 & 1.28 \\
\hline MCMB-25 & 6.45 & 6.34 & 98.29 & 1.71 \\
\hline GrF-5 & 7.62 & 7.50 & 98.42 & 1.58 \\
\hline GrF-15 & 7.03 & 6.90 & 98.15 & 1.85 \\
\hline GrF-25 & 6.45 & 6.21 & 96.27 & 3.73 \\
\hline
\end{tabular}

The matrix of MCMB-Cu composites is a compound made up of $\mathrm{Cu}, \mathrm{Fe}$, and $\mathrm{Al}$ particles. During the preparation process, the carbon atoms in the MCMB may diffuse into the matrix and react with the iron phase to form pearlite [20]. The combination of pearlite, $\mathrm{Cu}, \mathrm{Fe}$, and $\mathrm{Al}$ particles generates a complex matrix structure, which plays a vital role in the mechanical and tribological properties 
of the composites. To analyze the structure, Figure $2 \mathrm{c}$ displays the BSEM image of the MCMB-25 sample. Some pale gray and black laminar particles are distributed uniformly throughout the white matrix. During the BSEM imaging process, if an element in the sample has a higher atomic number, it has a higher brightness in the image. $\mathrm{Cu}$ has a higher brightness (i.e., the white region) owing to its larger atomic number than those of the other elements. The lamellar pearlite is composed of the thin lamellas of ferrite and cementite oriented one over the other. This implies that the black/gray lamellar particles are pearlites. As the basic component of pearlites, both cementite and ferrite may be formed by the eutectoid reaction of iron and carbon during the cooling of the samples after sintering, and the carbon content of cementite is far higher than that of ferrite. Therefore, the cementite phase shows a darker color than that of the ferrite phase in the BSEM image. In this manner, the black parts in these lamellar particles are the cementite phase, and pale gray parts are ferrite. The remaining pure black particles in the matrix are aluminum. During the preparation process of the MCMB-Cu and GrF-Fe composites, because the melting point of aluminum $\left(650^{\circ} \mathrm{C}\right)$ is far lower than the sintering temperature of $980^{\circ} \mathrm{C}$, aluminum will form a liquid phase, and penetrate into the inter space of the $\mathrm{Cu}$ and/or Fe particles. The $\mathrm{Al}$ will increase the density of the composite, and diffuse into the copper to enhance the sinterability of $\mathrm{Cu}$ particles.

In contrast, Figure $2 \mathrm{~d}$ shows the BSEM image of the matrix of the GrF-25 composite. It can be seen that the matrix of the GrF-25 composite has a microstructure similar to that of the matrix of the MCMB-25 composite shown in Figure 2c. Meanwhile, it is found that the iron phase in the matrix of GrF-25 composite mainly exists in the form of a large amount of ferrite (i.e., pale gray region) and a small amount of pearlite (i.e., lamellar particles). Compared with the GrF-25 composite, there are more black/gray laminar particles in the matrix of the MCMB- 25 composite. Upon further observation, it turns out that the black parts of these laminar particles in the MCMB- 25 composite have larger total areas than those of the GrF-25 composite. This implies that the former contains more cementite than the latter.

To further prove this conclusion, the matrices of the two groups of composites were investigated by energy dispersive spectroscopy (EDS). The EDS analysis results (i.e., chemical distribution maps) are shown in Figure $3 \mathrm{c}-\mathrm{j}$. As can be seen from these figures, the matrix carbon content of the MCMB-Cu composite is higher than that of the $\mathrm{GrF}-\mathrm{Cu}$ composite. These findings suggest that, during the preparation process of the $\mathrm{MCMB}-\mathrm{Cu}$ composite, more carbon atoms diffuse from the MCMB into the matrix and react with the iron phase, thereby generating more cementite because MCMB might have higher carbon diffusion activity than that of GrF.

To verify this conclusion, an MCMB(GrF)-Fe composite with a volume ratio (MCMBs or $\mathrm{GrFs} / \mathrm{Fe}$ ) of 1:3 was prepared by the preparation process used for the MCMB-Cu composites. The phases present in the composite could be identified by the Vickers microhardness test. Therefore, we measured the Vickers microhardness of the MCMB-Fe and GrF-Fe composites, and the corresponding microstructures are shown in Figure 4. Specially, the Vickers hardness values of the S points, F points, and remaining position are $978 \mathrm{Hv}, 87 \mathrm{Hv}$, and $200-250 \mathrm{Hv}$, respectively. The diffusion of carbon atoms into the iron generates the formation of cementite, pearlite, and ferrite, and the corresponding standard hardness values are about $800 \mathrm{Hv}, 180-250 \mathrm{Hv}$, and $80 \mathrm{Hv}$, respectively. Therefore, we concluded that the MCMB-Fe composite mainly consists of pearlite and cementite, while the composition of the GrF-Fe composite mainly includes ferrite and pearlite. Additionally, the chemical compositions of the $\mathrm{S}$ and $\mathrm{F}$ points were analyzed by EDS. The EDS analysis results are shown in Table 3. It can be seen that the carbon content of the $S$ points is higher than that of the $F$ points. These results confirm that more carbon atoms diffuse from the MCMB into the iron phase and generate more cementite, because MCMBs have a higher carbon diffusion capacity than that of $\mathrm{GrF}$, which is an attribute that will be further discussed below. 

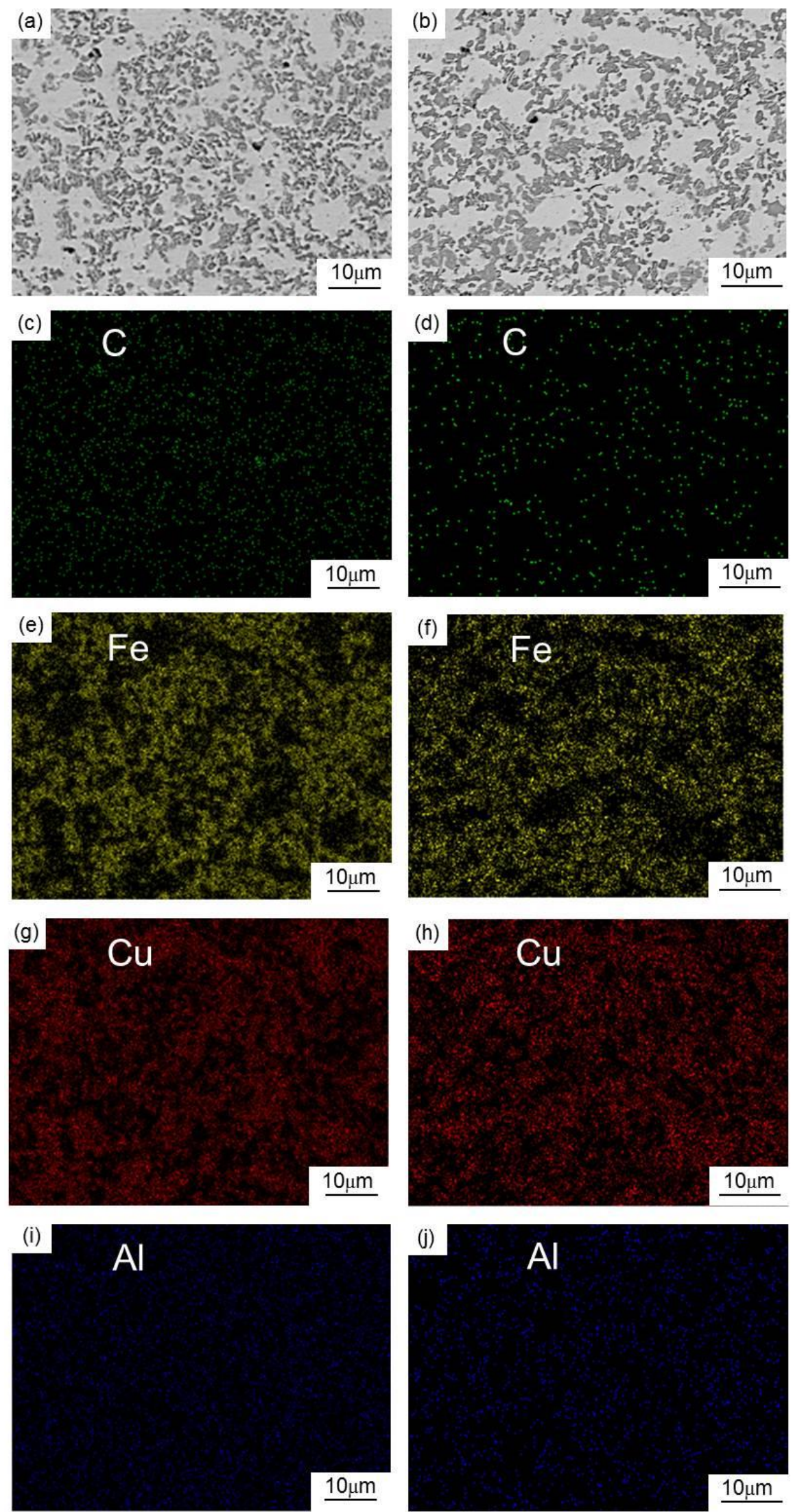

Figure 3. BSEM of the matrices of the (a) MCMB-25 and (b) GrF-25 composites, and energy dispersive spectroscopy (EDS) maps of the matrices of the (c,e,g,i) MCMB-25 and (d, $\mathbf{f}, \mathbf{h}, \mathbf{j})$ GrF-25 composites. 

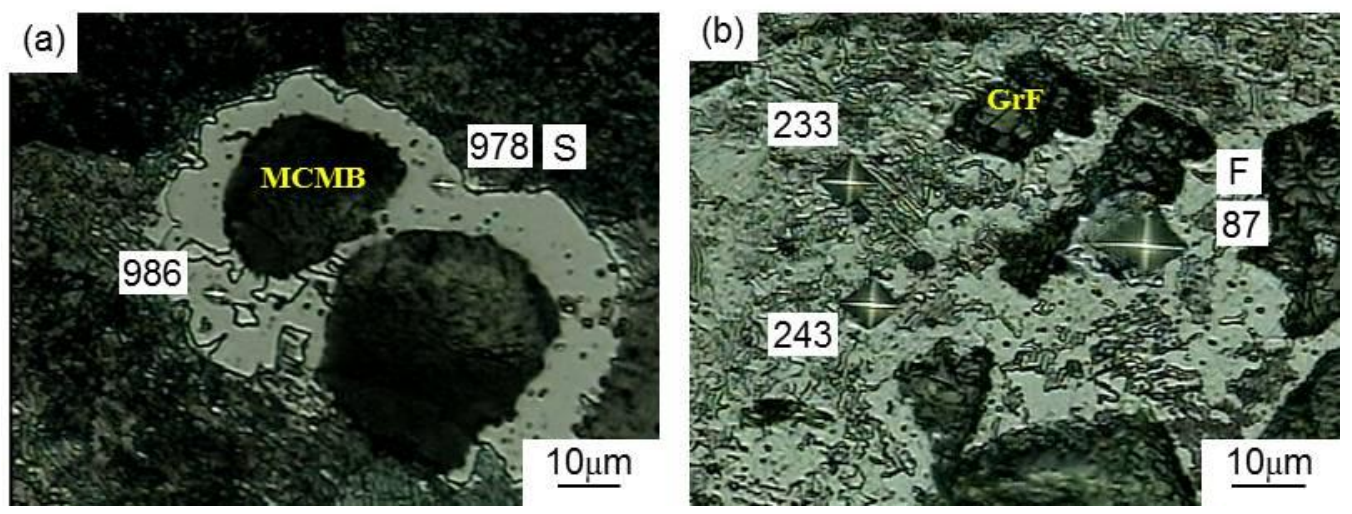

Figure 4. Microstructures of the (a) MCMB-Fe composite and the (b) GrF-Fe composite.

Table 3. Chemical compositions of the different points.

\begin{tabular}{lccc}
\hline Composition (S Marker) & Element & Weight Percent \% & Atom Percent \% \\
\hline & C K & 6.59 & 24.71 \\
& Fe K & 93.41 & 75.26 \\
& total & 100 & 100 \\
\hline Composition (F Marker) & C K & 0.01 & 0.05 \\
& Fe K & 99.99 & 99.95 \\
& total & 100 & 100 \\
\hline
\end{tabular}

The activity of graphite crystals is usually associated with the distance between adjacent carbon atom layers in their crystal structure $[17,21]$. Here, we evaluate and compare the activities of MCMB and GrF by analyzing their crystal structures using XRD. Figure 5 shows the XRD patterns of the MCMB and GrF powders using silicon as an internal standard. From Figure 5, the angles of the diffraction peaks of Si can be obtained. In fact, Si has standard angles of the diffraction peaks. The exact value of the measurement error was obtained by comparing the measurement angles of the diffraction peak with the angle of the diffraction peak standard. Then, this error was subtracted from the measured angles of the MCMB and GrF powders to obtain the actual angles of the diffraction peaks. It can be seen that the diffraction profile of the (111) reflection of silicon corresponds to the diffraction angle $2 \theta\left(28.438^{\circ}\right)$. However, the true angle of the (111) diffraction peak is $28.443^{\circ}$ [22]. The difference (i.e., measurement error) between the true and measured diffraction angles was obtained. There are some sharp peaks in the diffraction profiles, suggesting that both MCMB and GrF exhibit an ordered graphite crystal structure. In addition, the diffraction angles $2 \theta$ of the (002) crystal plane corresponding to the MCMB and $\mathrm{GrF}$ are $26.468^{\circ}$ and $26.514^{\circ}$, respectively. Then, the correct angle of the (002) diffraction peak of the MCMB and GrF was obtained by eliminating the measurement error. Using Equation (1), the interplanar spacings $d_{002}$ of MCMB and GrF were calculated as $0.3367 \mathrm{~nm}$ and $0.3350 \mathrm{~nm}$, respectively. The interplanar spacing $d_{002}$ represents the distance between adjacent carbon atom layers in the graphite crystal structure [22]. Obviously, the interplanar spacing between adjacent carbon atom layers in the MCMB is larger than that in GrF. The crystal structures of the MCMB and GrF are formed by stacked carbon atom layers held together by Van der Waals forces. The number of carbon atom pairs (forming Van der Waals force interactions) per unit area in the interfaces between adjacent layers in the crystal structure of MCMB may be the same as that of the interfaces between adjacent layers in the crystal structure of GrF. The Van der Waals force interactions between adjacent carbon atom layers are affected by the distance between them. Compared with GrF, the crystal structure of MCMB has a greater interplanar spacing, thus leading to a weaker interaction between the carbon atom layers. Therefore, under thermal fields, the carbon atoms in MCMB are more easily moved out of their lattice than are those in $\mathrm{GrF}$, subsequently diffusing into other mediums (i.e., Fe) to form compounds, suggesting that MCMB has a higher carbon diffusion activity than that of GrF. Furthermore, the weaker 
layer-layer interaction also leads to easier layer separation of the crystal structure of MCMB than that of GrF, thus generating a thinner cut sheet from MCMB when subjected to friction loading.

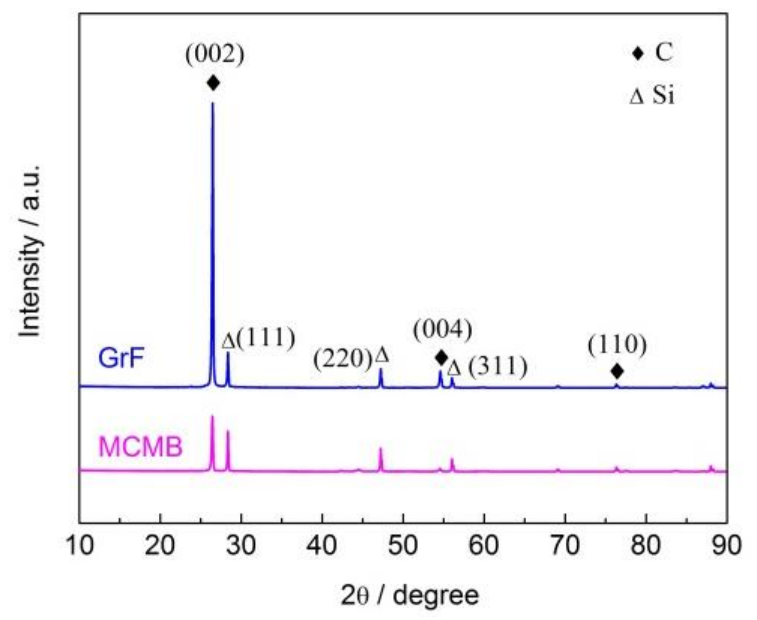

Figure 5. X-ray diffraction patterns of the MCMB and GrF powders.

\subsection{Mechanical Properties}

\subsubsection{Brinell Hardness}

Figure 6 depicts the Brinell hardness value of the MCMB-Cu composite and $\mathrm{GrF}-\mathrm{Cu}$ composite at the MCMB and GrF volume contents of 5\%,15\%, and 25\%. With the same MCMB and GrF contents, the Brinell hardness of the MCMB-filled composites is higher than that of the composites filled with GrF. Specially, the Brinell hardness values of the MCMB-25 composite and GrF-25 composite are 101 and $75 \mathrm{HBW}$, respectively, and the former is nearly 1.5 times the latter. For the same MCMB and GrF contents, compared with the $\mathrm{GrF}-\mathrm{Cu}$ composite, more $\mathrm{Fe}_{3} \mathrm{C}$ particles are generated in the $\mathrm{MCMB}-\mathrm{Cu}$ composite owing to the higher carbon diffusion activity of MCMB than of GrF. The hardness of these $\mathrm{Fe}_{3} \mathrm{C}$ particles is higher than that of other composite components such as $\mathrm{Cu}, \mathrm{Fe}$, and $\mathrm{Al}$. Furthermore, the dispersion of $\mathrm{Fe}_{3} \mathrm{C}$ particles in these composites is beneficial in preventing dislocation movement in the crystals of copper and iron and enhancing the deformation resistance during loading [23]. Therefore, a combination of more $\mathrm{Fe}_{3} \mathrm{C}$ particles and their dispersion strengthening effect results in a higher hardness of the MCMB-Cu composites than that of the $\mathrm{GrF}-\mathrm{Cu}$ composites at the same $\mathrm{Al}_{2} \mathrm{O}_{3}$ content. When the content of MCMB and GrF is $25 \%$, as shown in Figure $2 \mathrm{c}$, d, the total amounts of black parts (i.e., $\mathrm{Fe}_{3} \mathrm{C}$ ) in the black/gray laminar particles in the MCMB-25 composite are far higher than those of the GrF-25 composite, resulting in a higher hardness of the MCMB-25 composite. A similar result has also been reported by Ram Prabhu et al. [20], who have shown that, the higher the volume fraction of the reinforcement in the metal matrix, the higher the hardness of the composite. It can also be observed that, as the MCMB content increases from 5\% to 25\%, the hardness of the MCMB-Cu composite gradually decreases owing to the lower hardness of the MCMB particles [24]. As the MCMB content increases, the copper, iron, and aluminum mixture content decreases to keep the total volume content of all compounds constant. The negative effect of increasing the MCMB content is much stronger than the positive effect of the accompanying $\mathrm{Fe}_{3} \mathrm{C}$ increasing effect on the hardness of the composites. This trend and the associated physical mechanisms are analogous to the effect of the GrF content on the hardness of the GrF-Cu composites. On the basis of Archard's relation [25], a high hardness value is correlated with a better wear resistance; these trends are of interest while examining the wear rate of the composites. 


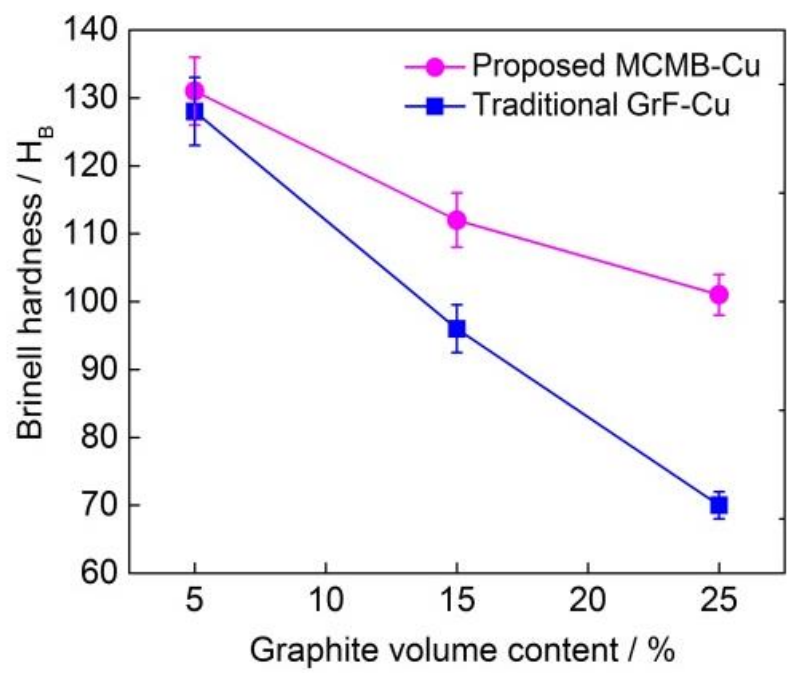

Figure 6. Brinell hardness value of the MCMB-Cu and $\mathrm{GrF}-\mathrm{Cu}$ composites with different $\mathrm{MCMB}$ and GrF volume contents.

\subsubsection{Flexural Strength}

Figure 7 shows the flexural strengths of the MCMB-Cu composite and $\mathrm{GrF}-\mathrm{Cu}$ composite at the different $\mathrm{MCMB}$ and $\mathrm{GrF}$ volume contents of $5 \%, 15 \%$, and $25 \%$. With the same MCMB and GrF content, the flexural strengths of the MCMB-filled composites are higher than those of the composites filled with GrF. When MCMB and GrF particles are present in the composites, the stress concentration factor near the tips of the MCMBs should be considerably lower than that near the flake graphite; thus, under loading, brittle cracking is less intense in the composite containing MCMBs than in that containing flake graphite. Furthermore, dispersion strengthening of the MCMB-Cu composite by $\mathrm{Fe}_{3} \mathrm{C}$ formation is also an important factor in enhancing the MCMB-Cu composite strength. The combined effect of these aspects leads to a higher flexural strength of the MCMB-Cu composites in comparison with that of the $\mathrm{GrF}-\mathrm{Cu}$ composites. It can also be observed that, as the MCMB content increases from $5 \%$ to $25 \%$, the flexural strength of the MCMB-Cu composites gradually decreases. The strength and hardness of MCMB particles are extremely low, so their presence can induce a notch effect in the matrix, which is the likely rupture origin in the composites, and consequently, the flexural strength is reduced at higher MCMB contents.

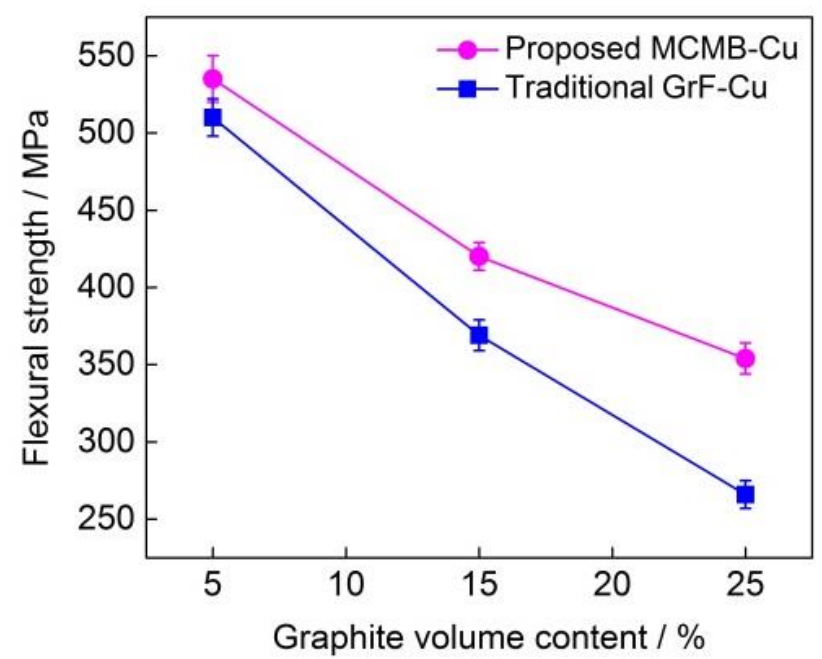

Figure 7. Flexural strengths of the MCMB-Cu and GrF-Cu composites under different MCMB and GrF volume contents. 


\subsection{Tribological Properties}

\subsubsection{Friction Coefficient}

Figure 8 shows the friction coefficients of MCMB-Cu composites and $\mathrm{GrF}-\mathrm{Cu}$ composites under different MCMB and GrF volume contents. As can be seen in Figure 8, the MCMB-Cu composites have lower friction coefficients than those of the $\mathrm{GrF}-\mathrm{Cu}$ composites at the same MCMB and $\mathrm{GrF}$ content. When the composites are subjected to surface friction loads, plastic deformation of the metallic matrix occurs, and brittle MCMB or GrF around the matrix are extruded to break into small graphite debris, resulting in the formation of a graphite-rich tribofilm on the friction surface of the composites [26]. Chen et al. [13] also proved that the solid lubricant migrates from the matrix to the worn surface and forms a tribofilm mainly containing the solid lubricant during the friction process of metal matrix composites. As the crystal structure of MCMB has a larger interlayer spacing and a weaker interlayer interaction than those of $\mathrm{GrF}$, thinner and smaller MCMB debris are generated under surface friction on the MCMB-Cu composites, as shown in Figure 9. Therefore, a smoother tribofilm is formed on the friction surface, leading to a lower friction coefficient of the MCMB-Cu composites in comparison with the $\mathrm{GrF}-\mathrm{Cu}$ composites.

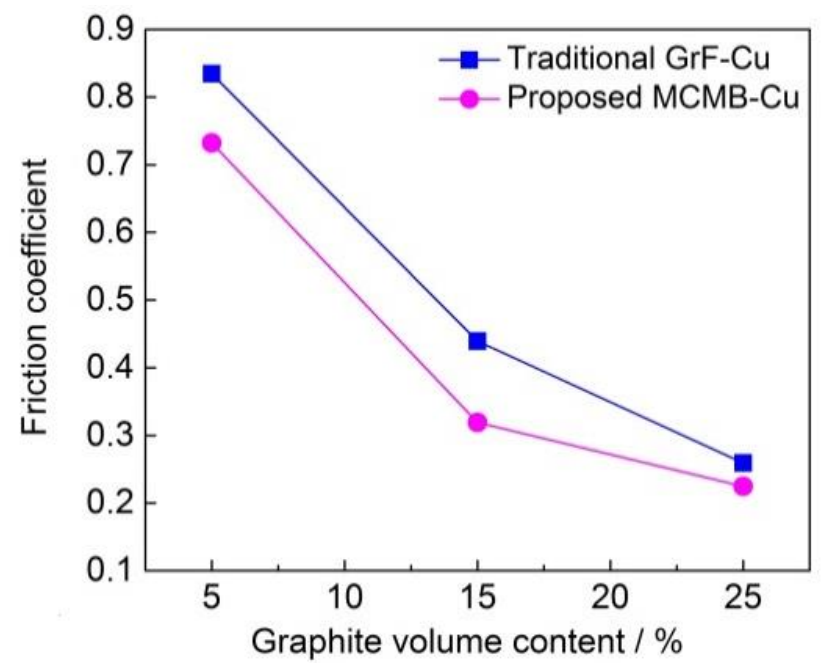

Figure 8. Friction coefficients of the MCMB-Cu and $\mathrm{GrF}-\mathrm{Cu}$ composites under different $\mathrm{MCMB}$ and GrF volume contents.

The friction coefficient of the MCMB-Cu composites decreases from 0.84 to 0.25 as the MCMB content increases from $5 \mathrm{vol} . \%$ to $25 \mathrm{vol} . \%$. As the MCMB content increases, the content of the metal mixture matrix, which provides the main resistance to sliding friction during the friction process, decreases in the composites. This results in a decrease of the friction force and, thereby, the decline of the friction coefficient under the same pressure loading. Meanwhile, the MCMB-Cu composites with a higher $\mathrm{MCMB}$ contents generate more MCMB debris, thus forming smoother MCMB-rich tribofilms, which is beneficial to reducing the friction coefficient. The combined effects of these aspects result in a significant reduction of the friction coefficient of the MCMB-Cu composite with increasing MCMB contents. 

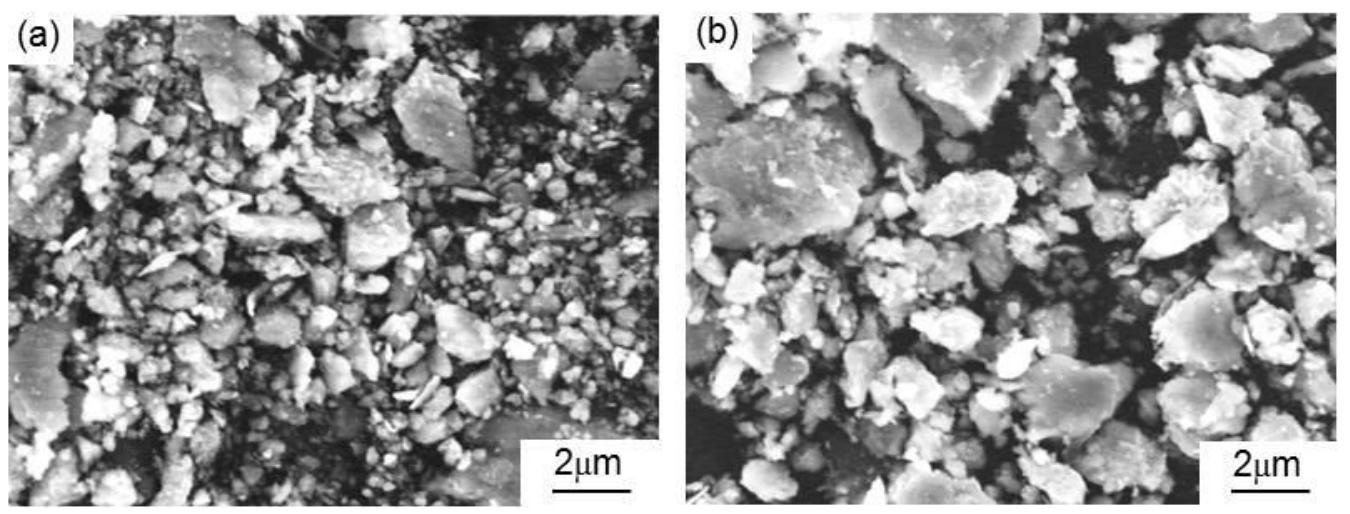

Figure 9. SEM images of the graphite debris of (a) the MCMB-Cu composites and (b) the $\mathrm{GrF}-\mathrm{Cu}$ composites.

\subsubsection{Wear Rate}

Figure 10 shows the wear rates of the $\mathrm{MCMB}-\mathrm{Cu}$ composites and $\mathrm{GrF}-\mathrm{Cu}$ composites under different $\mathrm{MCMB}$ and $\mathrm{GrF}$ volume contents. It can be seen that the MCMB-Cu composites have a lower wear rate than that of the $\mathrm{GrF}-\mathrm{Cu}$ composites under the same MCMB and GrF content. As mentioned before, compared with the $\mathrm{GrF}-\mathrm{Cu}$ composites, the metal matrix of the MCMB-Cu composites contains more $\mathrm{Fe}_{3} \mathrm{C}$ particles owing to the higher carbon diffusion activity of MCMB than of GrF. The high hardness of these $\mathrm{Fe}_{3} \mathrm{C}$ particles contributes to a higher hardness of MCMB-Cu composites, showing higher deformation resistance, which results in a smaller compressive deformation of the composites subjected to an initial surface pressure during friction. Meanwhile, these $\mathrm{Fe}_{3} \mathrm{C}$ particles also play an enhancing role in the strength of the $\mathrm{MCMB}-\mathrm{Cu}$ composites. As the friction process continues, $\mathrm{MCMB}-\mathrm{Cu}$ composites show higher shear resistance, leading to the formation of some shallower grooves on their friction surfaces, thus reducing the wear rate of $\mathrm{MCMB}-\mathrm{Cu}$ composites. The high hardness and strength of MCMB-Cu composites play an important role in reducing the wear rate of composites, which has been illustrated in the work of Ram et al. [20]. On the other hand, the shape of the flake GrFs is sharper than that of the spherical MCMBs. Under the same loading, the interfacial stress between the GrF and matrix is higher than that at the MCMB/matrix interface [27], which results in easier crack initiation and propagation [28] and the flaking of more GrFs and metal matrix, forming some holes on the friction surface, as shown in Figure 11a,c. It can be concluded that the flaking in the MCMB-25 composite occurs in smaller areas and at shallower depths compared with that of the GrF-25 composite. Compared with GrF debris, the thinner and smaller MCMB debris can effectively fill the holes of the worn surface of the MCMB- 25 composite, which may also be a key factor behind the reduced flaking areas, in addition to the smooth $\mathrm{MCMB} /$ matrix interface and more cementite presence. This phenomenon also implies that more uniform and compact tribofilms can be formed on the friction surfaces of MCMB-Cu composites in comparison with $\mathrm{GrF}-\mathrm{Cu}$ composites. Such a tribofilm facilitates the reduction of the adhesive wear between the MCMB-Cu composites and hard counters. The combined effect of these aspects leads to a lower wear rate of the MCMB-Cu composites in comparison with that of the $\mathrm{GrF}-\mathrm{Cu}$ composites.

We can also find from Figure 10 that, with the increasing MCMB contents, the wear rates of the $\mathrm{MCMB}-\mathrm{Cu}$ composites decrease. As has been proven, a higher MCMB content enhances the amount of $\mathrm{Fe}_{3} \mathrm{C}$ generated in the matrix of the MCMB-Cu composites, which is beneficial to reducing their wear rate. A higher $\mathrm{MCMB}$ content also leads to the formation of a more uniform and compact tribofilm, weakening the adhesive wear rate of the composites. 


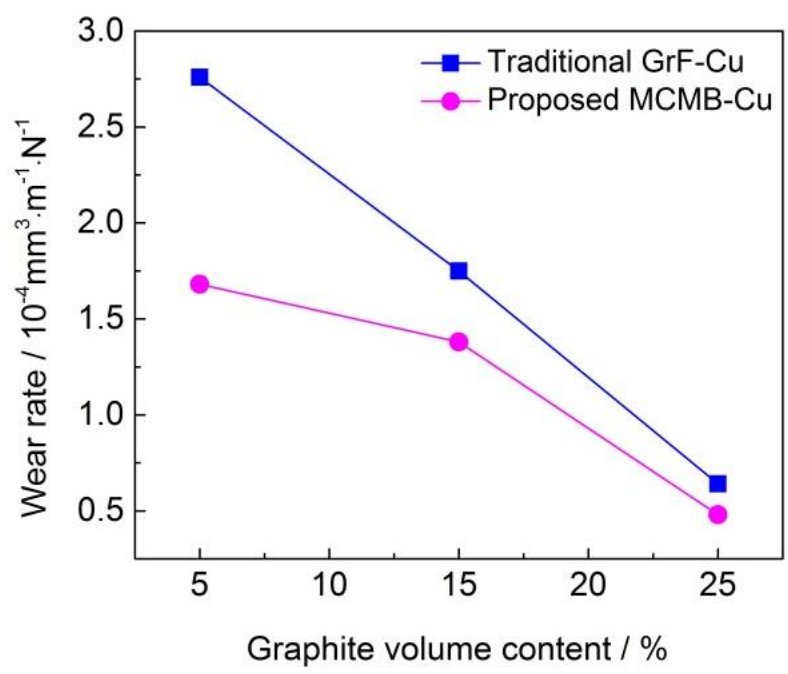

Figure 10. Wear rates of the $\mathrm{MCMB}-\mathrm{Cu}$ and $\mathrm{GrF}-\mathrm{Cu}$ composites under different $\mathrm{MCMB}$ and $\mathrm{GrF}$ volume contents.
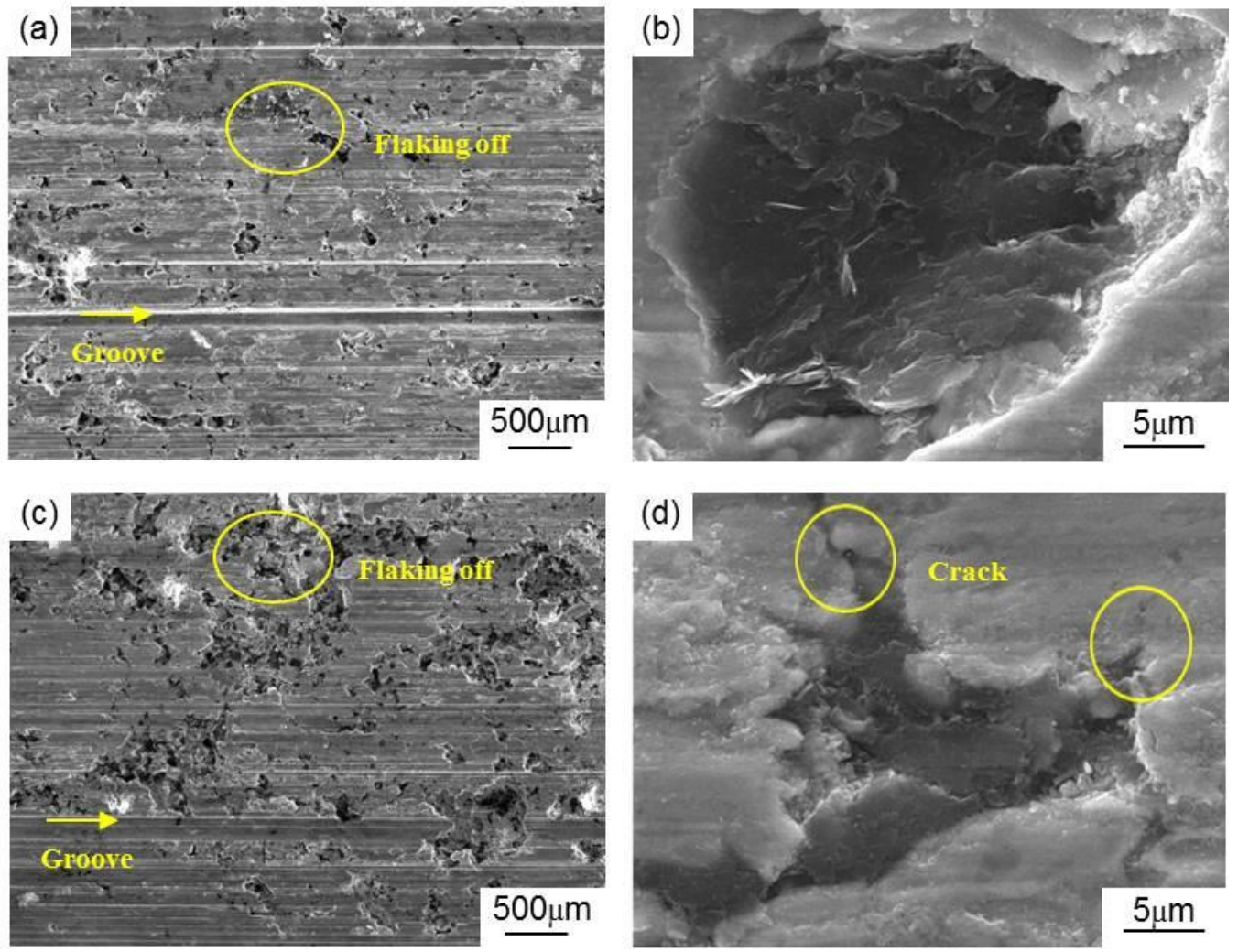

Figure 11. Wear surface morphologies of the (a,b) MCMB-Cu composites and (c,d) GrF-Cu composites.

At present, GrF-metal matrix friction materials have been widely used in train brake equipment in place of early metal friction materials [29,30]. Their certain self-lubricity addresses the blocking problem that occurs during the braking process using metal friction materials. In this work, we have developed MCMB-Cu composites that might be used as friction materials. Our analyses in Section 3.3 demonstrate that $\mathrm{MCMB}-\mathrm{Cu}$ composites exhibit lower friction coefficients and wear rates than do $\mathrm{GrF}-\mathrm{Cu}$ friction materials with the same solid lubricant content, suggesting a better self-lubricity of the former compared with that of the latter. This also implies that MCMB is a promising solid lubricant for use in metal-based friction materials in comparison with GrF. Furthermore, $\mathrm{MCMB}-\mathrm{Cu}$ composites have higher hardness values than $\mathrm{GrF}-\mathrm{Cu}$ composites under the same $\mathrm{MCMB}$ and $\mathrm{GrF}$ 
content. These results also illustrate that adding a relatively small amount of MCMB allows $\mathrm{MCMB}-\mathrm{Cu}$ composites to present an equivalent friction coefficient to that of $\mathrm{GrF}-\mathrm{Cu}$ composites containing more GrF. MCMB-Cu composites also have higher hardness values and strengths than those of $\mathrm{GrF}-\mathrm{Cu}$ materials. These characteristics are advantageous in designing brake composites with desirable friction coefficients and high hardness and strength through adjusting the content of MCMB.

\section{Conclusions}

MCMB-metal matrix self-lubricity materials were successfully developed for the first time by powder metallurgy. The tribological properties and lubrication mechanisms of the composites have been elucidated. It was demonstrated that composites using MCMB as the solid lubricant have lower friction coefficients and wear rates than do composites containing flake graphite, and both the friction coefficients and wear rates of the two groups of composites gradually decrease with the solid lubricant content. The weaker interlayer bonding of MCMB results in smaller MCMB debris, and consequently, a uniform, compact, and smooth MCMB-rich tribofilm can be formed on the friction surfaces of MCMB-Cu composites, which contributes to the low friction coefficients of the composites. The high activity of $\mathrm{MCMB}$ enhances carbon diffusion in Fe to form more $\mathrm{Fe}_{3} \mathrm{C}$, resulting in the high strength and hardness of the composites and, thereby, the low wear rate of MCMB-Cu composites. As a novel friction material, MCMB-Cu composites could be a promising alternative for use in tribological applications.

Author Contributions: Conceptualization, H.-X.G. and J.-F.Y.; methodology, H.-X.G. and J.-F.Y.; investigation, H.-X.G. and J.-F.Y.; data curation, H.-X.G. and J.-F.Y.; writing-review and editing, H.-X.G. and J.-F.Y.; project administration, H.-X.G.; funding acquisition, J.-F.Y. All authors have read and agreed to the published version of the manuscript.

Funding: This research was funded by National Key R \& D Program of China, grant number 2017 YFB0310300 and 2017YFB0903803; National Natural Science Foundation of China, grant number 51672209; and Natural Science Basic Research Plan in Shaanxi Province of China, grant number 2016JQ5046.

Conflicts of Interest: The authors declare no conflict of interest.

\section{References}

1. Xiao, Y.L.; Yao, P.P.; Zhou, H.B.; Zhang, Z.Y.; Gong, T.M.; Zhao, L.; Zuo, X.T.; Deng, M.W.; Jin, Z.X. Friction and wear behavior of copper matrix composite for spacecraft rendezvous and docking under different conditions. Wear 2014, 320, 127-134. [CrossRef]

2. Nayak, D.; Ray, N.; Sahoo, R.; Debata, M. Analysis of tribological performance of Cu hybrid composites reinforced with graphite and TiC using factorial techniques. Tribol. Trans. 2014, 57, 908-918. [CrossRef]

3. Ram Prabhu, T.; Varma, V.K.; Vedantam, S. Tribological and mechanical behavior of multilayer $\mathrm{Cu} / \mathrm{SiC}+\mathrm{Gr}$ hybrid composites for brake friction material applications. Wear 2014, 317, 201-212. [CrossRef]

4. Chen, W.Y.; Yu, Y.; Cheng, J.; Wang, S.; Zhu, S.Y.; Liu, W.M.; Yang, J. Microstructure, mechanical properties and dry sliding wear behavior of $\mathrm{Cu}_{-} \mathrm{Al}_{2} \mathrm{O}_{3}$-graphite solid-lubricating coatings deposited by low-pressure cold spraying. J. Therm. Spray Technol. 2018, 27, 1652-1663. [CrossRef]

5. Xiao, Y.L.; Zhang, Z.Y.; Yao, P.P.; Fan, K.Y.; Zhou, H.B.; Gong, T.M.; Zhao, L.; Deng, M.W. Mechanical and tribological behaviors of copper metal matrix composites for brake pads used in high-speed trains. Tribol. Int. 2018, 119, 585-592. [CrossRef]

6. Zhan, Y.Z.; Zhan, G.D. Graphite and $\mathrm{SiC}$ hybrid particles reinforced copper composite and its tribological characteristic. J. Mater. Sci. Lett. 2003, 22, 1087-1089. [CrossRef]

7. Ram Prabhu, T. Effects of solid lubricants, load, and sliding speed on the tribological behavior of silica reinforced composites using design of experiments. Mater. Des. 2015, 77, 149-160. [CrossRef]

8. Chen, B.M.; Bi, Q.L.; Yang, J.; Xia, Y.Q.; Hao, J.C. Tribological properties of Cu-based composites and in situ synthesis of TiN/TiB 2 . Mater. Sci. Eng. A 2008, 491, 315-320. [CrossRef]

9. Xu, Z.S.; Zhang, Q.X.; Huang, X.J.; Liu, R.; Zhai, W.Z.; Yang, K.; Zhu, Q.S. An approximate model for the migration of solid lubricant on metal matrix self-lubricating composites. Tribol. Int. 2016, 93, 104-114. [CrossRef] 
10. Rajkumar, K.; Aravindan, S. Tribological performance of microwave sintered copper-TiC-graphite hybrid composites. Tribol. Int. 2011, 44, 347-358. [CrossRef]

11. Zhan, Y.Z.; Zhan, G.D. The role of graphite particles in the high-temperature wear of copper hybrid composites against steel. Tribol. Lett. 2006, 17, 91-98. [CrossRef]

12. Wang, J.X.; Zhang, R.J.; Xu, J.; Wu, C.; Chen, P. Effect of the content of ball-milled expanded graphite on the bending and tribological properties of copper-graphite composites. Mater. Des. 2013, 47, 667-671. [CrossRef]

13. Chen, B.M.; Bi, Q.L.; Yang, J.; Xia, Y.Q.; Hao, J.C. Tribological properties of solid lubricants (graphite, h-BN) for Cu-based P/M friction composites. Tribol. Int. 2008, 41, 1145-1152. [CrossRef]

14. Shao, Z.; Sun, Y.; Liu, W.; Xu, J.; Wu, C.; Chen, P. Effects of multi-phase reinforcements on microstructures, mechanical and tribological properties of $\mathrm{Cu} / \mathrm{Ti}_{3} \mathrm{SiC}_{2} / \mathrm{C} / \mathrm{BN} / \mathrm{GNPs}$ nanocomposites sintered by vacuum hot-pressing and hot isostatic pressing. Metals 2016, 6, 324. [CrossRef]

15. Mochida, I.; Korai, Y.; Ku, C.H. Chemistry of synthesis, preparation and application of aromatic-derived mesophase pitch. Carbon 2000, 38, 305-328. [CrossRef]

16. Brooks, J.D.; Taylor, G.H. The formation of graphitizing carbons from the liquid phase. Carbon 1965, 3 , 185-186. [CrossRef]

17. Norfolk, C.; Kaufmann, A.; Mukasyan, A.; Mukasyan, A.; Varma, A. Processing of mesocarbon microbeads to high-performance materials: Part III. High-temperature sintering and graphitization. Carbon 2006, 44, 301-306. [CrossRef]

18. Boz, M.; Kurt, A. The effect of $\mathrm{Al}_{2} \mathrm{O}_{3}$ on the friction performance of automotive brake friction materials. Tribol. Int. 2007, 40, 1161-1169. [CrossRef]

19. Jiang, X.S.; Liu, W.X.; Li, J.R.; Shao, Z.Y.; Zhu, D.G. Microstructures and mechanical properties of $\mathrm{Cu} / \mathrm{Ti}_{3} \mathrm{SiC}_{2} / \mathrm{C} / \mathrm{MWCNTs}$ composites prepared by vacuum hot-pressing sintering. J. Alloys Compd. 2015, 618, 700-706.

20. Ram Prabhu, T.; Varma, V.K.; Vedantam, S. Effect of SiC volume fraction and size on dry sliding wear of $\mathrm{Fe} / \mathrm{SiC} /$ graphite hybrid composites for high sliding speed applications. Wear 2014, 309, 1-10. [CrossRef]

21. Fujimoto, H. A new estimation method for the degree of graphitization for random layer lattices. Carbon 2010, 48, 3446-3453. [CrossRef]

22. Iwashita, N.; Park, C.R.; Fujimoto, H.; Shiraishi, M.; Inagaki, M. Specification for a standard procedure of $X$-ray diffraction measurements on carbon materials. Carbon 2004, 42, 701-714. [CrossRef]

23. Zhang, X.J.; Dong, P.Y.; Zhang, B.G.; Tang, S.Y.; Yang, Z.R.; Chen, Y.; Yang, W.C. Preparation and characterization of reduced graphene oxide/copper composites incorporated with nano-SiO 2 particles. J. Alloys Compd. 2016, 671, 465-472. [CrossRef]

24. Zum Gahr, K.H. Abrasive wear of microstructures with internal notches. Strength Met. Alloys 1979, 1, 225-230.

25. Archard, J.F. Contact and rubbing of flat surfaces. J. Appl. Phys. 1953, 24, 981. [CrossRef]

26. Kováčik, J.; Emmer, Š.; Bielek, J. Effect of composition on friction coefficient of Cu-graphite composites. Wear 2008, 265, 417-421. [CrossRef]

27. Meng, Q.; Wang, Z. Prediction of interfacial strength and failure mechanisms in particle-reinforced metal-matrix composites based on a micromechanical model. Eng. Fract. Mech. 2015, 142, 170-183. [CrossRef]

28. Meng, Q.; Wang, Z. Creep damage models and their applications for crack growth analysis in pipes: A review. Eng. Fract. Mech. 2019, 205, 547-576. [CrossRef]

29. Ferrer, C.; Pascual, M.; Busquets, D.; Rayón, E. Tribological study of Fe-Cu-Cr-graphite alloy and cast iron railway brake shoes by pin-on-disc technique. Wear 2010, 268, 784-789. [CrossRef]

30. Mann, R.; Magnier, V.; Brunel, J.F.; Brunel, F.; Dufrénoy, P.; Henrion, M. Relation between mechanical behavior and microstructure of a sintered material for braking application. Wear 2017, 386, 1-16. [CrossRef]

(C) 2020 by the authors. Licensee MDPI, Basel, Switzerland. This article is an open access article distributed under the terms and conditions of the Creative Commons Attribution (CC BY) license (http://creativecommons.org/licenses/by/4.0/). 